\title{
Analysis of the mitochondrial and nuclear genomes of two basidiomycetes, Coprinus cinereus and Coprinus stercorarius
}

\author{
Christine A. Weber ${ }^{*}$, Michael E. S. Hudspeth ${ }^{* *}$, Gordon P. Moore ${ }^{* * *}$, and Lawrence I. Grossman ${ }^{* * * *}$ \\ Department of Cellular and Molecular Biology, Division of Biological Sciences, The University of Michigan, Ann Arbor, MI 48109, USA
}

Summary. The mitochondrial and nuclear genomes of Coprinus stercorarius and $C$. cinereus were compared to assess their evolutionary relatedness and to characterize at the molecular level changes that have occurred since they diverged from a common ancestor. The mitochondrial genome of $C$. stercorarius $(91.1 \mathrm{~kb})$ is approximately twice as large as that of $C$. cinereus $(43.3 \mathrm{~kb})$. The pattern of restriction enzyme recognition sites shows both genomes to be circular, but reveals no clear homologies; furthermore, the order of structural genes is different in each species. The $C$. stercorarius mitochondrial genome contains a region homologous to a probe derived from the yeast mitochondrial varl gene, whereas its nuclear genome does not. By contrast, the $C$. cinereus nuclear, but not mitochondrial, genome contains a region homologous to the varl probe. Only a small fraction of either the nuclear or mitochondrial genomes, perhaps corresponding to the coding sequences, is capable of forming duplexes in interspecies solution reassociations, as measured by binding to hydroxylapatite. Those sequences capable of reassociating were found to have approximately $15 \%$ divergence for the mitochondrial genomes and $7 \%-15 \%$ divergence for the nuclear genomes, depending on the conditions of reassociation.

\footnotetext{
Present addresses:

* Biomedical Sciences Division, L-452, Lawrence Livermore National Laboratory, University of California, Livermore, CA 94550 , USA

** Plant Molecular Biology Center, Department of Biological Sciences, Northern Illinois University, DeKalb, IL 601152861, USA

*** Gene Expression Group, NEN Products Division, DuPont BRL-500-3, North Billerica, MA 01862, USA

**** Science, 1333 H Street, N. W., Washington, DC 20005, USA

Offprint requests to: $\mathrm{C}$. A. Weber
}

Key words: Mitochondrial DNA - Coprinus - DNADNA reassociation - Gene mapping

\section{Introduction}

Phylogenetic classification has traditionally been based on morphological and developmental features in conjunction with the fossil record. For many groups, however, paucity of the fossil record and lack of consistently distinguishing anatomical characteristics render these classical methods problematic.

An alternative approach for classification is the use of biochemical characteristics, such as the electrophoretic or immunological properties of proteins. More recently, the amino acid sequence of proteins (e.g. Wilson et al. 1977 ) or the nucleotide sequence of DNA (see below) has been used extensively as a character in phylogenetic studies. Slowly evolving macromolecules, such as the protein actin or the $5 \mathrm{~S}$ ribosomal RNA, are useful for comparison of distantly related species, while differences in more rapidly evolving molecules, such as fibrinopeptides or mitochondrial DNA (mtDNA), can be used to deduce phylogenetic relationships among more closely related species. Comparisons of mitochondrial or nuclear DNAs have been particularly useful since DNAs can be compared for overall homology by hybridization and thermal melting (e.g. Sibley and Ahlquist 1983, 1984), within selected shorter segments by comparison of gene organization and restriction enzyme cleavage sites (e.g. Ferris et al. 1981), or in detail by determination of the nucleotide sequence of individual regions (Perler et al. 1980; Efstratiadis et al. 1980; Cohn et al. 1984) or entire small genomes.

MtDNAs, because of their rapid rate of evolutionary divergence (Brown et al. 1979), have been particularly 
Table 1. Sources of yeast mitochondrial gene probes. The COII probe was obtained as a bacterial plasmid containing a $2.4 \mathrm{~kb} H p a \mathrm{II}$ fragment cloned into the PstI site of pBR322. The S-RNA sequence region is numbered from the $5^{\prime}$-end of the processed product as determined by $\mathrm{Li}$ and Tzagoloff (1982). Strain BD11 lacks the $40 \mathrm{bp}$ insert at positions $440-479$ found in the strain sequenced by Sor and Fukuhara (1980). A12/48 is an intron ${ }^{-}$strain and, thus, lacks bases 2689-3831 and 2466-2532 and contains two additional A residues between $2534-2535$

\begin{tabular}{|c|c|c|c|c|c|}
\hline Gene & $\begin{array}{l}\text { Petite } \\
\text { strain }\end{array}$ & $\begin{array}{l}\text { Restriction } \\
\text { digest }\end{array}$ & $\begin{array}{l}\text { Fragment } \\
\text { size, bp }\end{array}$ & $\begin{array}{l}\text { Region } \\
\text { in sequence }\end{array}$ & Reference \\
\hline$S$-RNA & BD11 & HhaI/BamHI & 637 & $+44 /+720$ & Sor and Fukuhara 1980 \\
\hline$L$-RNA & $\mathrm{A} 12 / 48$ & $H i n c$ II & 3,352 & $-671 /+3,888$ & Sor and Fukuhara 1983 \\
\hline varI & A17/10 & $\operatorname{Hinf} \mathrm{I} / M b o \mathrm{I}$ & 665 & $+86 /+750$ & Hudspeth et al. 1982 \\
\hline $\mathrm{COB}$ & DS400/A12 & HinfI & 478 & $+56 /+533$ & Nobrega and Tzagoloff 1980 \\
\hline $\mathrm{COI}$ & DS6/A407 & HinfI & 246 & $+8,093 /+8,338$ & Bonitz et al. 1980 \\
\hline COII & & HinfI & 351 & $+80 /+430$ & Fox 1979; Coruzzi and Tzagoloff 1979 \\
\hline COIII & DS40 & Hind III & 383 & $+498 /+880$ & Thalenfeld and Tzagoloff 1980 \\
\hline ATPase 6 & DS14 & $M b o \mathrm{I} / E c o R \mathbf{I}$ & 404 & $+294 /+697$ & Macino and Tzagoloff 1980 \\
\hline ATPase 9 & DS400/A3 & AluI & 75,84 & $+20 /+178$ & Macino and Tzagoloff 1979 \\
\hline
\end{tabular}

useful as characters in evolutionary studies (e.g. Brown et al. 1982). The fungal mtDNAs studied to date have shown a high level of diversity. Although approximately the same number and identity of genes are present, genome size among fungi varies between 19 and $175 \mathrm{~kb}$ (reviewed in Grossman and Hudspeth 1985). MtDNA characteristics requiring more detailed study have been compared primarily among ascomycetes, which differ in the nature and number of open reading frames, in gene order, in the organellar location of at least one gene, and in their use of the genetic code (Wallace 1982; Gray 1982; Gray and Doolittle 1982; Grossman and Hudspeth 1985).

The fungi present a good example of a group wherein phylogenetic classification has been difficult (e.g. Whittaker 1969; Shaffer 1975; Walker and Doolittle 1982). In particular, relationships within the Basidiomycetes are poorly established (Shaffer 1975). Accordingly, we have begun a comparison of the nuclear and mitochondrial genomes of the Basidiomycetes. We present here physical and genetic maps for the mtDNA of two basidiomycetes. The two species examined, cinereus and stercorarius, are common mushrooms that represent two sections of the genus Coprinus (Singer 1975). Data reported here indicate that their mtDNAs differ appreciably in size, sequence, and gene order. Consistent with their levels of mitochondrial divergence, little relatedness is seen between their nuclear DNAs. Interestingly, sequences hybridizing to the Saccharomyces cerevisiae varl gene are found in the nucleus of one and the mitochondria of the other.

\section{Materials and methods}

Strains. C. cinereus ATCC no. 18064 and C. stercorarius ATCC no. 28258 were obtained from the American Type Culture Col- lection (Bethesda, Md.) and grown, respectively, on YMG $(0.4 \%$ yeast extract / $1.0 \%$ malt extract / $0.4 \%$ glucose) and PYG $(0.125 \%$ peptone $/ 0.125 \%$ yeast extract $/ 0.5 \%$ glucose $)$. Growth of fungal mycelia for DNA isolation was in liquid bubble culture at room temperature. Cultures were maintained on plates containing growth medium plus $1.2 \%$ agar. $S$. cerevisiae mitochondrial gene probes (Table 1) were isolated from petite (rho ${ }^{-}$) strains, except for the COII probe, which was kindly provided in a bacterial plasmid by Thomas Fox (Cornell University). The petite strains containing the large and small ribosomal RNA genes were kindly provided by Philip Perlman (Ohio State University). The remaining $r o^{-}$strains were generously made available by Alexander Tzagoloff (Columbia University).

Isolation and purification of DNAs. MtDNA from $S$. cerevisiae petite mutants was isolated from bisbenzimide-CsCl gradients as described by Hudspeth et al. (1980). Plasmid DNA was prepared (Maniatis et al, 1982) from bacterial cells grown in a minimal medium, using chloramphenicol for plasmid amplification, and lysed with sodium dodecylsulfate (SDS).

$C$. cinereus and $C$. stercorarius mitochondrial and nuclear DNAs were isolated by a modification of the method of Hudspeth et al. (1983). Mycelia were filtered through a nylon stocking, rinsed with distilled water, resuspended in $0.1 \mathrm{M}$ Tris/0.1 M EDTA ( $\mathrm{pH} 7.5$ ), refiltered through nylon, and pressed dry between stacks of paper towels. The tissue was then ground to a fine powder in liquid nitrogen with a mortar and pestle. Total DNA was collected by ethanol precipitation and centrifuged in a $\mathrm{CsCl}$ gradient (density $1.57 \mathrm{gm} / \mathrm{cc}$ ) containing $600 \mu \mathrm{g} / \mathrm{ml}$ ethidium bromide in a Beckman Ty65 rotor at $36,000 \mathrm{rpm}$ for $48 \mathrm{~h}$ : This step removed a visible component that otherwise contaminated the DNA in CsCl-bisbenzimide gradients and probably consists of polysaccharide.

After removal of ethidium bromide by $n$-butanol extractions, mitochondrial and nuclear DNAs were further purified by repeated centrifugation as above in $\mathrm{CsCl}$ gradients containing bisbenzimide (Hudspeth et al. 1980). The A+T-rich mtDNA formed the upper of the two bands found. For use in reassociation reactions, the DNAs were further purified by extractions with watersaturated $n$-butanol to remove bisbenzimide, followed by digestions with RNases $A$ and $T_{1}$ (at final concentrations of $10 \mu \mathrm{g} / \mathrm{ml}$ and 0.045 units $/ \mathrm{ml}$, respectively) at $37^{\circ} \mathrm{C}$ for $15 \mathrm{~min}$, then with proteinase $\mathrm{K}$ (at a final concentration of $10 \mu \mathrm{g} / \mathrm{ml}$ ) at room tem- 


\section{Coprinus cinereus}

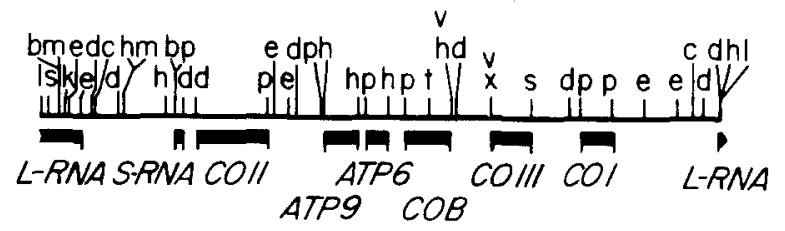

$\stackrel{4 \mathrm{~kb}}{\longrightarrow}$

Coprinus stercorarius

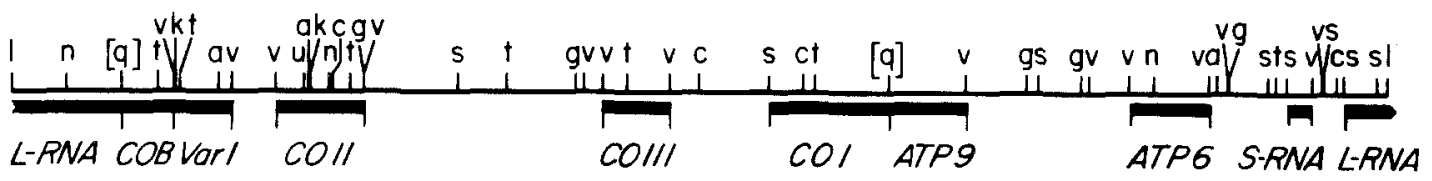

Fig. 1. Physical maps of mitochondrial genomes from $C$. cinereus and C. stercorarius. The circular genomes were arbitrarily linearized at the single $S a l \mathrm{I}$ site in each species. Heavy lines beneath each map indicate fragments that hybridized to the nine probes listed in Table 1. Abbreviations: a, ApaI; b, BalI; c, ClaI; d, HindIII; e, EcoRI; g, BglI; h, HpaII; k, KpnI; 1, SalI; m, BamHI; n, NcoI; p, PstI; q, HaeII; s, SphI; t, StuI; u, PvuI; v, AvaI; x, XhoI. Three additional HindIII fragments $(0.03,0.04,0.17 \mathrm{~kb})$ and two additonal EcoRI fragments $(0.02,0.18 \mathrm{~kb})$ were not localized on the $C$. cinereus map, and five additional $A v a \mathrm{I}$ fragments $(0.013,0.018,0.079,0.098,0.11 \mathrm{~kb})$ were not localized for $C$. stercorarius. Haell sites are bracketed [q] to indicate that only a few of the numerous sites are shown (to delineate hybridization regions). C. cinereus mtDNA lacks recognition sites for $A p a I, B g l I$ and $N c o l$. Hybridizing regions were localized with EcoRI, HindIII, HpaII and PstI single and double digestions for C. cinereus and AvaI, SphI and HaeII digestions for C. stercorarius. For localizing COIII in $C$. cinereus, $A v a I$ and $S p h I$ were also used. ATPase 9 homology in $C$. stercorarius mtDNA could be further localized to a $1.6 \mathrm{~kb}$ HaeII fragment within the region indicated

perature with gentle shaking for $1 \mathrm{~h}$. The DNA was then extracted several times with phenol: chloroform: isoamyl alcohol $(25: 24$ : 1 ), adjusted to $0.3 \mathrm{M}$ sodium acetate, and precipitated with ethanol.

Restriction endonuclease digestion and labelling. DNA digestions with restriction endonucleases were carried out under conditions recommended by the manufacturers. DNA digested with restriction enzymes for mapping of cleavage sites was sometimes endlabelled using $\alpha_{-32}$ P-dNTPs and the Klenow fragment of DNA polymerase $I$ by the method of Brown (1980), except reaction temperatures were approximately $15^{\circ} \mathrm{C}$.

Hybridization analysis. Mitochondrial or nuclear DNAs were digested with restriction enzymes, separated by electrophoresis and fragments transferred from agarose gels to nitrocellulose filters by the technique of Southern (1975). Hybridizations were carried out in $10 \%$ dextran sulfate by a modification of the method described by Maniatis et al. (1982). The salt concentrations were $6 \times$ SSC for hybridization and $3 \times$ SSC for washes (SSC = $150 \mathrm{mM} \mathrm{NaCl}+15 \mathrm{mM}$ sodium citrate). Hybridizations and washes were carried out at $40^{\circ} \mathrm{C}$ with the varl probe and at $50{ }^{\circ} \mathrm{C}$ with all other probes. The varl probe was hybridized at the lower temperature because of its unusually high $\mathrm{A}+\mathrm{T}$ content (Hudspeth et al. 1982; Zassenhaus et al. 1983). S. cerevisiae mitochondrial gene probes consisted of electroeluted restriction enzyme fragments of petite strain mtDNAs or plasmid clones (Table 1) and were labelled with $\alpha$-32P-dCTP by nick-translation.

DNA-DNA reassociation. Purified DNAs were sheared to an average single strand length of 300 to $1,300 \mathrm{bp}$ in $5 \mathrm{ml}$ of $0.015 \mathrm{M}$ $\mathrm{NaCl} / 0.5 \mathrm{M}$ Tris ( $\mathrm{pH} 7.5$ ) / $0.2 \mathrm{M}$ sodium acetate / 66\% glycerol with a Virtis homogenizer at $30,000 \mathrm{rpm}$ for $20 \mathrm{~min}$. The
DNA was precipitated with ethanol and resuspended in $0.2 \mathrm{M}$ sodium acetate ( $\mathrm{pH}$ 6.0). Single strand lengths were determined by electrophoresis in 1.2\% alkaline agarose gels (McDonell et al. 1977). Contaminating metal ions were removed from the DNA by passage over Chelex (Biorad, 200-400 mesh) equilibrated with $0.2 \mathrm{M}$ sodium acetate ( $\mathrm{pH} 6.0$ ).

MtDNAs were denatured in $0.12 \mathrm{M} \mathrm{PB}$ (sodium phosphate buffer, pH 6.8) and nuclear DNAs in $0.03 \mathrm{M} \mathrm{PB}$ in a Gilson spectrophotometer capable of controlled temperature increases. The lower salt buffer for nuclear DNAs was required to obtain complete denaturation; the $T_{m}$ (melting temperature) values expected in $0.12 \mathrm{M} \mathrm{PB}$ were calculated (Schildkraut and Lifson 1965). The temperature was raised from $25^{\circ} \mathrm{C}$ to $100^{\circ} \mathrm{C}$ at a rate of $1{ }^{\circ} \mathrm{C} / \mathrm{min}$, and denaturation was monitored by the change in optical density at $270 \mathrm{~nm}$.

Sequences able to form an intramolecular duplex ("snapback" structures) were removed from the mtDNAs and $32 \mathrm{P}$ labelled tracer DNAs by boiling for 5-10 min in $0.12 \mathrm{M} \mathrm{PB}$, followed by quenching in dry ice-ethanol and passage over HAP. To remove any highly repetitive sequences, as well as any "snapback" sequences, nuclear DNA was denatured by boiling for 5$10 \mathrm{~min}$, reassociated to $\mathrm{C}_{0} t$ (initial concentration $\times$ time) $2.4 \mathrm{M}$-s in $0.12 \mathrm{M} \mathrm{PB}$ at $25^{\circ} \mathrm{C}$ below the $\mathrm{T}_{\mathrm{m}}$, and passed over a HAP column (Britten et al. 1974). Single stranded DNA was eluted with $0.12 \mathrm{M} \mathrm{PB} / 0.06 \% \mathrm{SDS}$, followed by the elution of double stranded DNA with $0.5 \mathrm{M} \mathrm{PB} / 0.06 \%$ SDS. DNAs to be present as the radiolabelled low concentration species during reassociation reactions (i.e. tracer DNAs) were labelled by nick-translation using $\alpha-32 \mathrm{P}$-dCTP and DNA polymerase $\mathrm{I}$ at $15^{\circ} \mathrm{C}$ for $30 \mathrm{~min}$ as for the gene probes, except no DNase I was used. To ensure complete hybridization in thermal elution experiments, DNAs were reassociated to $100-800$ times the calculated driver $C_{0} t_{1 / 2}$ value in 0.41 M PB (Bonner et all. 1973; Britten et al. 1974). $\mathrm{C}_{0} \mathrm{t}$ 
Table 2. Site-to-site distances of the restriction site maps of $C$. cinereus and $C$. stercorarius. The distance between sites represents the averaged measured size. Sizes of some very small fragments $\left(^{*}\right)$ could not be determined directly for various technical reasons and were determined instead as the difference of the distances to a nearby site. The ClaI and StuI sites present on the C. cinereus map (Fig. 1) are not included because they were not positioned relative to the nearest site

C. cinereus

Enzyme

-

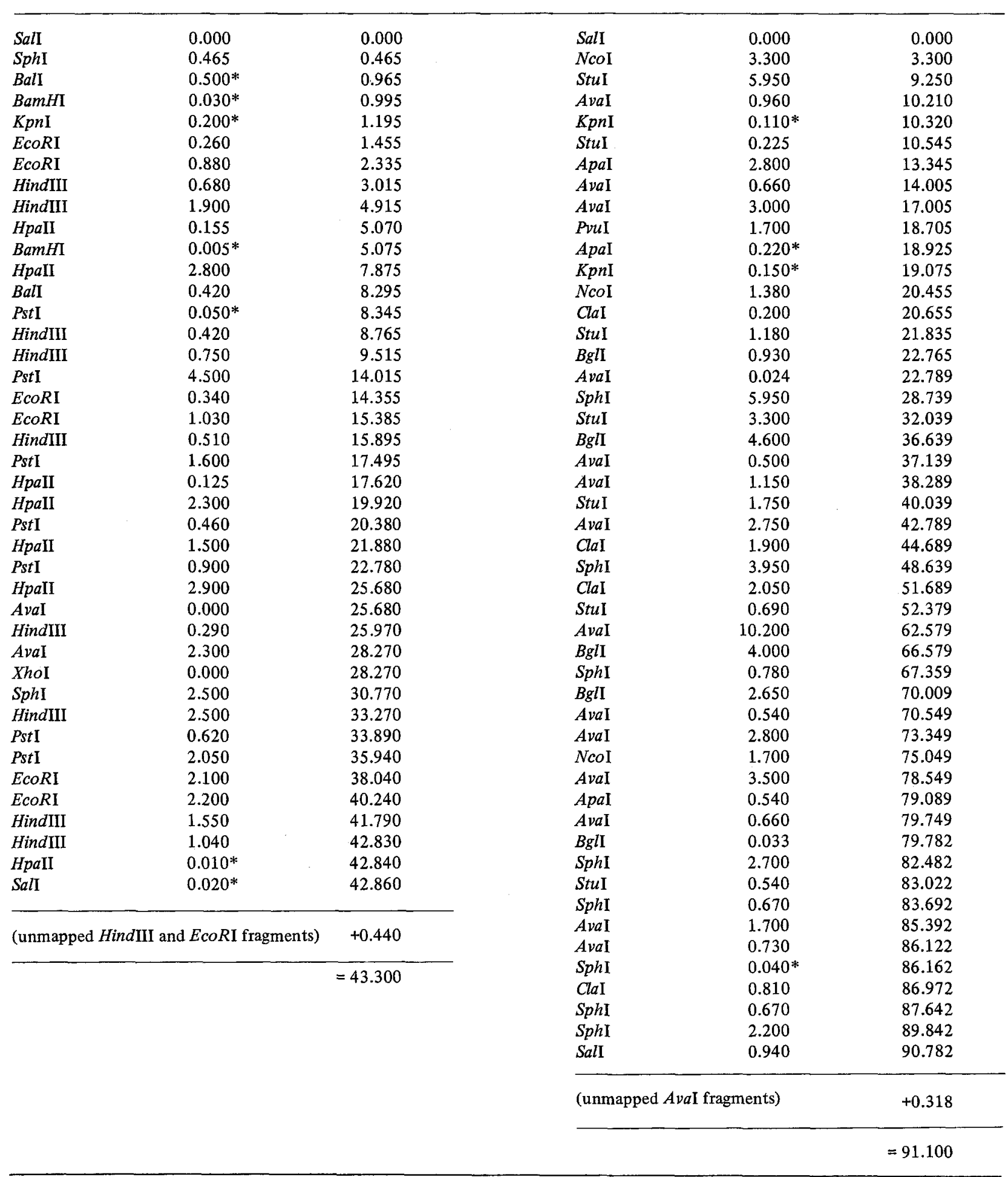

\section{C. stercorarius}

Enzyme Distance between $\quad$ Map position,
Distance between
sites, $\mathrm{kb}$

Distance between Map position,

Map position, sites, $\mathrm{kb}$ 


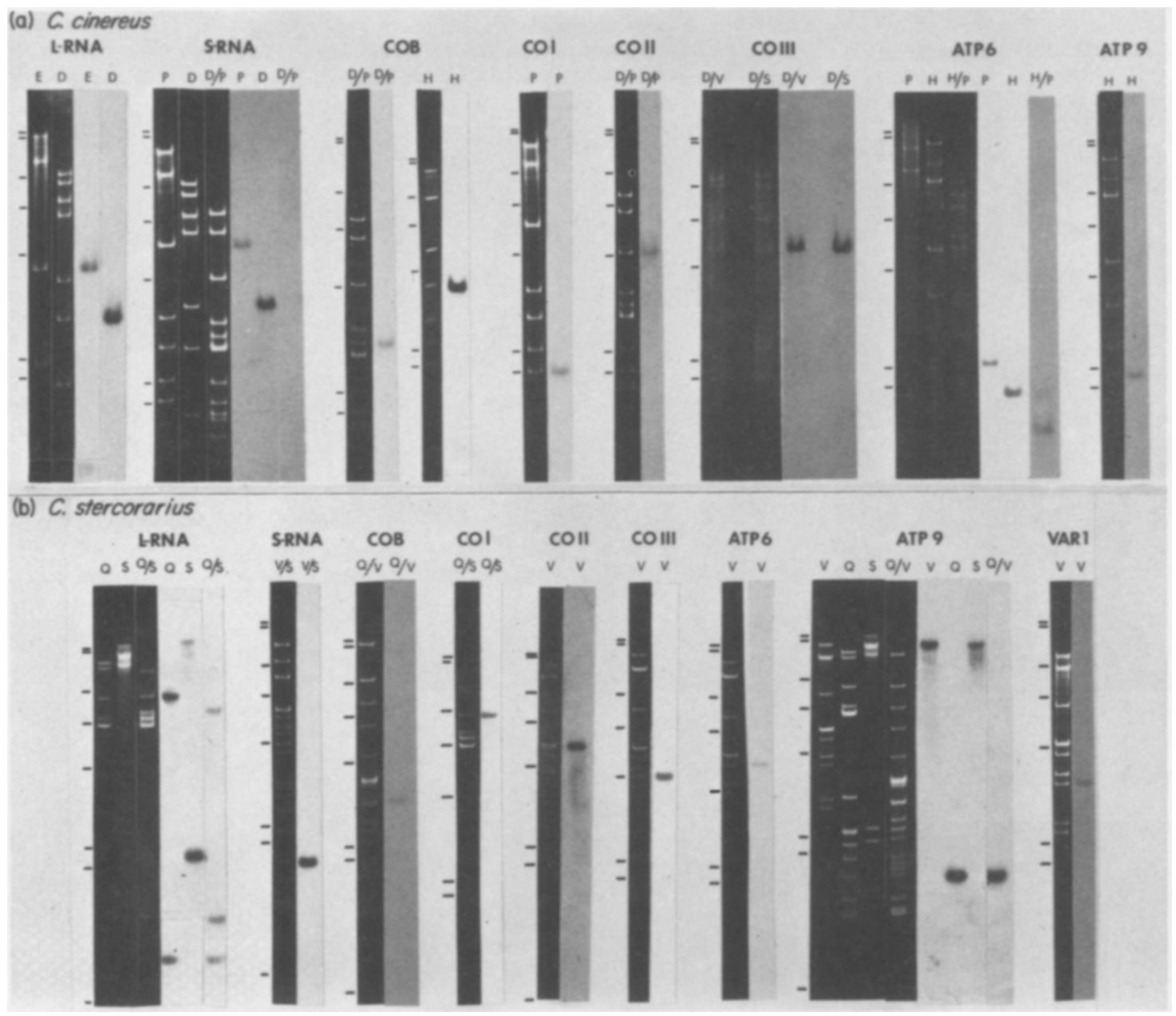

Fig. 2a, b. Southern hybridization between Coprinus mtDNA digests and yeast mitochondrial gene probes. For each probe, the $0.8 \%$ agarose gel stained with ethidium bromide is shown on the left, along with tick marks showing the positions of bacteriophage lambda DNA digested with HindIII; autoradiograms are on the right. The L-RNA autoradiogram in $\mathbf{b}$ is a composite of two different exposures of the same filter. Abbreviations: D, HindIII; E, EcoRI; H, HpaII; P, PstI; Q, HaeII; S, SphI; V, AvaI. The lambda x HindIII sizes are (kb) $27.5,23.1,9.4,6.7,4.4,2.3,2.0,0.56$, and 0.13

values for nuclear DNAs were calculated using a genome complexity of $3.7 \times 10^{7}$ nucleotides (Dutta et al. 1972). The mass ratio of driver to tracer was about 200 to 1 . The incubation temperatures were approximately $25^{\circ} \mathrm{C}$ below the $\mathrm{T}_{\mathrm{m}}$ values calculated for the homologous reactions, except where otherwise indicated. For thermal elution, reassociated DNAs were brought to $0.12 \mathrm{M}$ $\mathrm{PB} / 0.06 \%$ SDS and applied to HAP (Britten et al. 1974). Columns were equilibrated and DNA bound at $40^{\circ}-50^{\circ} \mathrm{C}$, after which the temperature was increased in $5^{\circ} \mathrm{C}$ increments to $100^{\circ} \mathrm{C}$ and the amount of DNA eluted at each temperature determined.

\section{Results}

\section{Location of restriction enzyme cleavage sites in mitochondrial $D N A$}

To examine the structure and organization of the $C . \mathrm{ci}$ nereus and $C$. stercorarius mitochondrial genomes, the positions of cleavage sites for 13 and 10 enzymes, respectively, were determined from single and double digests (Fig. 1). The genomes were found to be circular. The total genome sizes of $C$. cinereus $(43.3 \mathrm{~kb})$ and $C$. stercorarius $(91.1 \mathrm{~kb})$ were calculated by summing the average size of each fragment plus the average sizes of five very small unmapped fragments (Table 2).

No repetitive regions were detected in either genome by searching for repeated cleavage site patterns or by comparison of band intensities in ethidium bromidestained gels (Hudspeth et al. 1983); furthermore, no restriction enzyme cleavage sites are clearly shared be tween these two mtDNAs. The only apparent similarity in cleavage site position between the two genomes is the presence of a $S a l I-S p h I-C l a I$ cluster that lies at least partly within each L-RNA region. However, the significance of this apparent similarity is in doubt, since the site-to- 
a

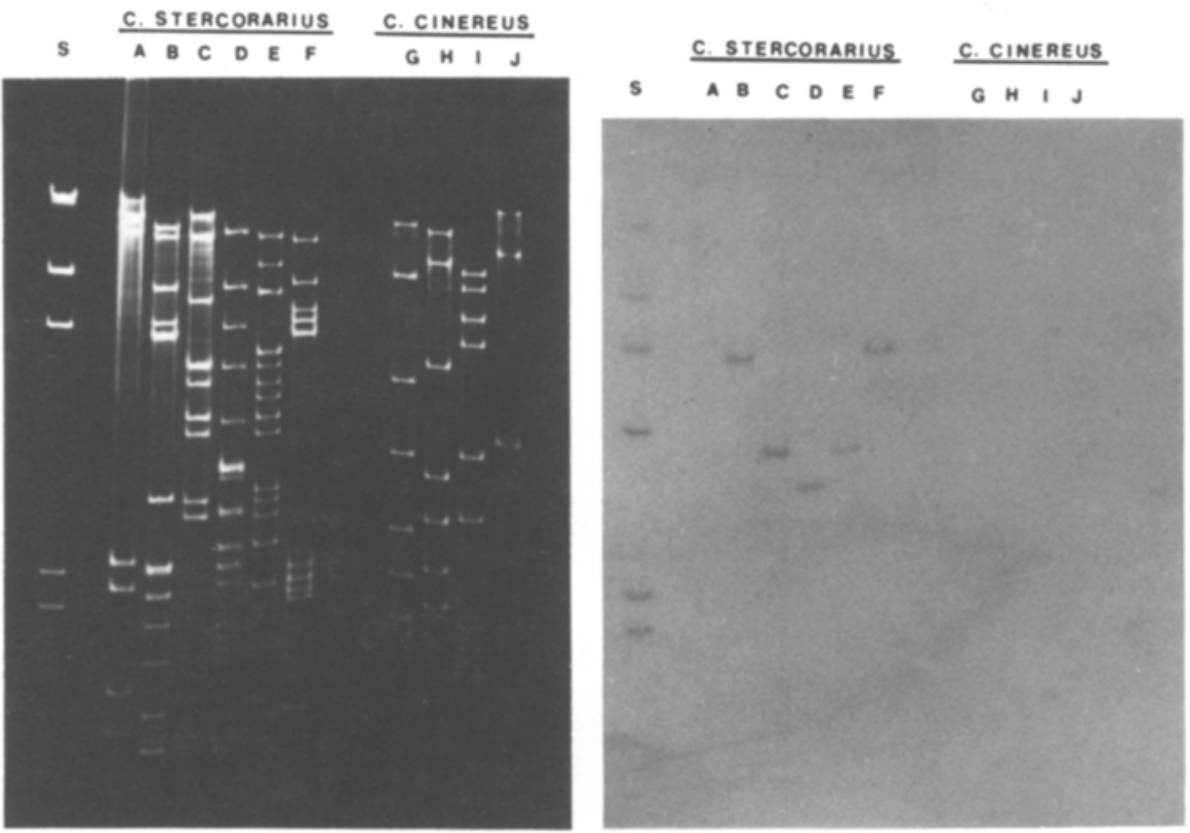

b

\section{STERCORARIUS C. CINEREUS}

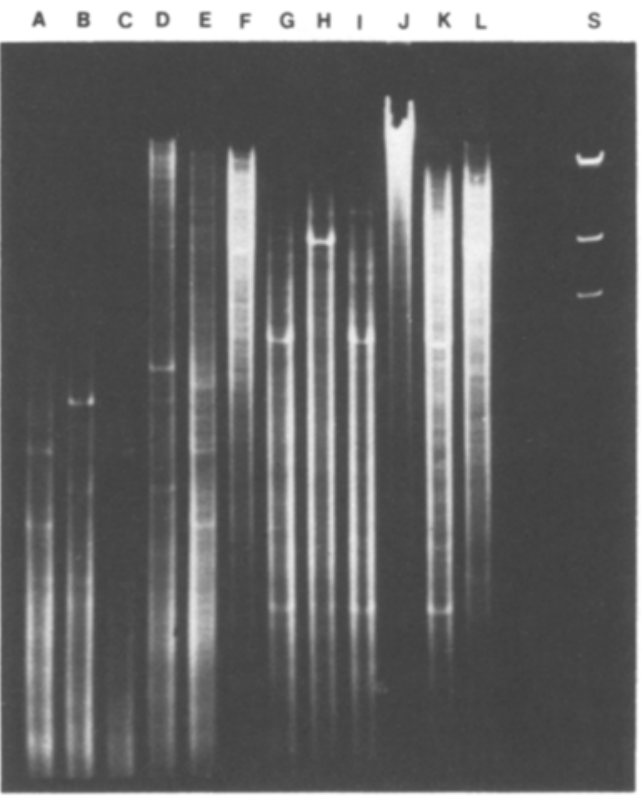

C. STERCORARIUS C.CINEREUS
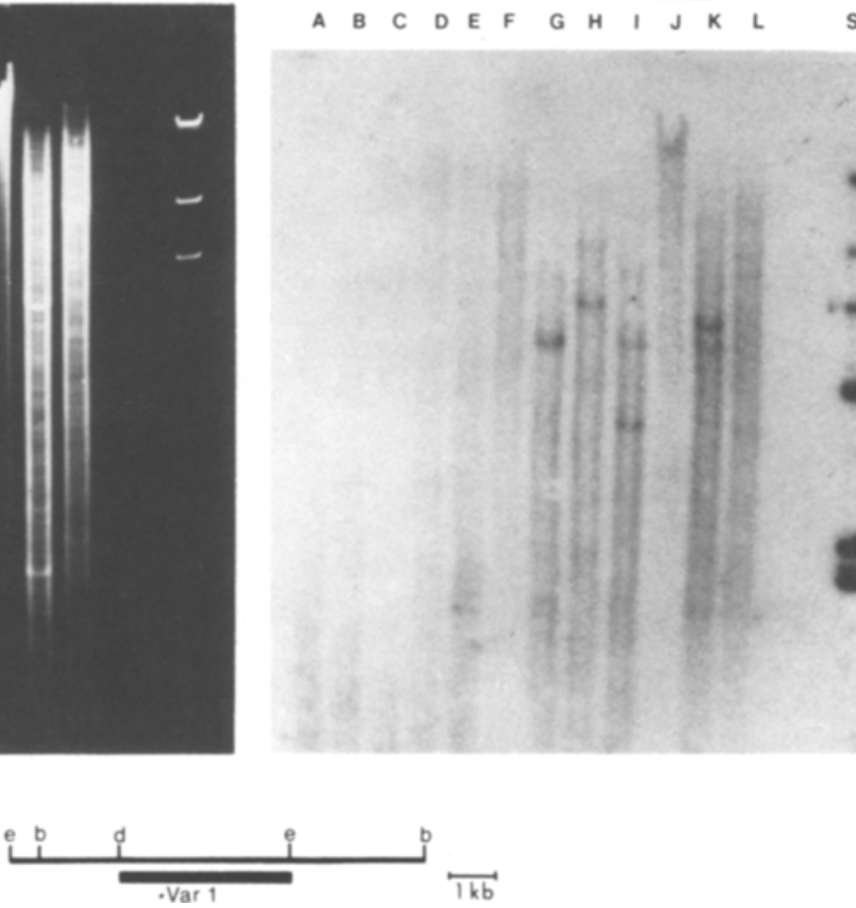

Fig. 3a-c. Southern hybridization of Coprinus mitochondrial and nuclear DNAs probed with varl. Mitochondrial (a) and nuclear (b) DNAs from $C$. stercorarius $(A-F)$ and $C$. cinereus $(G-J$ or $L$ ) were digested with various enzymes and separated on $0.8 \%$ agarose gels. After staining with ethidium bromide (left), Southern transfers were probed with varl and visualized by autoradiography (right). Lane $S$ is radiolabelled bacteriophage lambda DNA digested with $H i n d \mathrm{III}$. a $A, S p h \mathrm{I} ; B, H a e \mathrm{II} ; C, A v a \mathrm{I} ; D, H a e \mathrm{II}+A v a \mathrm{I} ; E, A v a \mathrm{I}+S p h \mathrm{I} ; F$, $H a e \mathrm{II}+$ SphI; G, HpaII; H, PstI I I,HindIII; J, EcoRI. b A,AvaI + BamHI; B,HaeII + BamHI; C, HaeII +AvaI; D, HaeII; E, AvaI; F, $B a m H I ; G, E c o R I+B a m H I ; H, H i n d \mathrm{III}+B a m H I ; I$, HindIII + EcoRI; $J$, HindIII (partial); K, EcoRI; L, BamHI. c Partial restriction enzyme site map of the $C$. cinereus nuclear region homologous to the var1 probe 


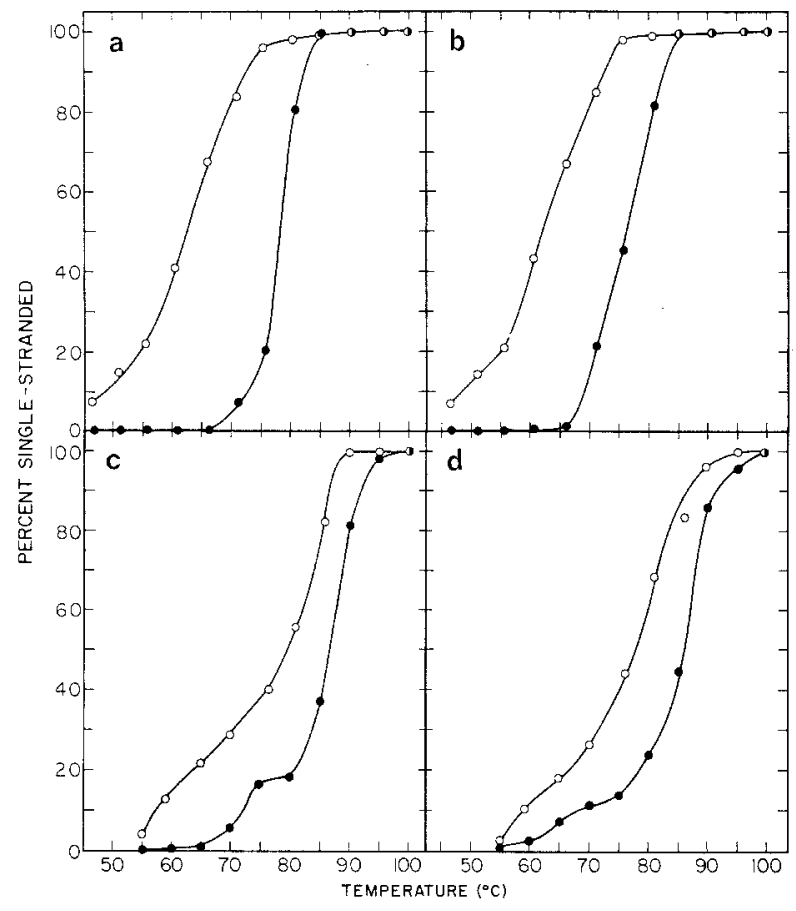

Fig. 4a-d. Thermal denaturation profiles of reassociated Coprinus mitochondrial and nuclear DNAs. Driver DNAs were denatured and reassociated in the presence of low concentrations of radioactive tracer DNAs, as described in Materials and methods. Denaturation was monitored by HAP column chromatography and the cumulative percent single stranded displayed vs. temperature. The DNAs used for each profile are listed in the order driver/tracer. a MtDNAs: $C$. cinereus $/ C$. cinereus $(\bullet), C$. stercorarius/C. cinereus (o); b MtDNAs: C. stercorarius/C. stercorarius $(\bullet), C$. cinereus/C. stercorarius ( $(0)$; $\mathrm{c}$ nuclear DNAs: $C$. cinereus $C$. cinereus $(\bullet), C$. stercorarius $/ C$. cinereus $(0)$; d nuclear DNAs: C. stercorarius/C. stercorarius $(\bullet), C$. cinereus/C. stercorarius $(o)$

site distances in each cluster are not identical and C. stercorarius has an additional $S p h \mathrm{I}$ site. While it would not be surprising to find sequence similarity and consequent sharing of restriction sites in this highly conserved region, further analysis would be required to determine the true relationship between these clusters. Overall, comparison of the physical maps of these two mitochondrial genomes indicates striking differences in both genome size and restriction enzyme cleavage pattern.

\section{Localization of mitochondrial genes}

Some of the protein-coding and the rRNA genes of the $C$. cinereus and $C$. stercorarius mitochondrial genomes were localized by Southern analysis, using as probes fragments of DNA derived from each of nine $S$. cerevisiae mitochondrial genes (Fig. 2). The maximum region of hybridization for the mitochondrial gene probes, which derive from only a portion of each gene (Table 1), is shown in Fig. 1.
The mitochondrial gene order in each species is seen to differ greatly; the only similarities are that three pairs of genes remain adjacent: the L-RNA and S-RNA genes, the ATP6 and ATP9 genes (coding for ATPase 6 and 9), and the $\mathrm{COI}$ and COIII genes (coding for cytochrome oxidase subunits 1 and 3 ). If inversion is excluded, consistent with the observation that most or all coding regions of the fungal mtDNAs examined are found on the same strand (Dujon 1983; Lang et al. 1983; Scazzochio et al. 1983), then no simple one or two step rearrangement could explain how this difference was generated during evolution. If inversion is permitted, then the two gene orders can be aligned with the following two operations on the $C$. stercorarius mtDNA map: (1) reverse the gene block bounded by COII and ATPase 6; and (2) transpose $\mathrm{COI}$ and COIII to the left of $\mathrm{COB}$.

In addition to the eight genes commonly found on $\mathrm{mtDNA}$, homology was found to the S. cerevisiae riboso$\mathrm{mal}$ protein gene, varl. Interestingly, varl showed homology to $C$. stercorarius mtDNA, but not $C$. cinereus mtDNA (Fig. 3a). In contrast, when var1 was used to probe Southern transfers of nuclear DNA from both species, $C$. cinereus, but not $C$. stercorarius, showed nuclear homology (Fig. 3b). Based on double digests, a partial restriction site map of the nuclear region showing varl homology could be determined (Fig. 3c).

\section{Mitochondrial DNA thermal melting studies}

The $\mathrm{G}+\mathrm{C}$ contents of $C$. cinereus and $C$. stercorarius $\mathrm{mtDNAs}$ were calculated from their native thermal melting profiles and found to be 27.0 and $30.6 \%$, respectively (Marmur and Doty 1962; Schildkraut and Lifson 1965).

The relatedness between the two mtDNAs was assessed by measuring the extent and stability of the heteroduplexes formed between them. Each mtDNA was used in turn as radioactively labelled tracer and hybridized with a large excess of unlabelled DNA derived either from the same species (homologous reactions) or from the other (heterologous reactions). The sequence homology between the DNA strands that formed duplexes was evaluated based on their thermal melting profiles. The homologous reassociations (Fig. 4; Table 3 ) were approximately $90 \%$ complete and melted over a narrow temperature range with $T_{m}$ values near those of native mtDNAs. The $\mathrm{T}_{\mathrm{m}}$ values of reassociated and native homologous duplexes cannot be directly compared, however, because they were measured in different ways (Geiduschek 1962).

In contrast to the homologous reassociations, the majority of DNA in the heterologous reactions did not reassociate (Table 3). The equivalent of $17.3 \mathrm{~kb}$ of the genome $(40.0 \%$ of $43.3 \mathrm{~kb})$ was reassociated with $C$. cinereus $\mathrm{mtDNA}$ as tracer, and $19.6 \mathrm{~kb}(21.5 \%$ of $91.1 \mathrm{~kb})$ 
Table 3. Stability of reassociated mitochondrial and nuclear DNAs. DNAs were sheared, denatured, and reassociated in 0.41 $\mathrm{M} \mathrm{PB}$ as described in methods. MtDNA was reassociated at $65^{\circ} \mathrm{C}$, nuclear DNA at $74{ }^{\circ} \mathrm{C}$. Melting profiles of reassociated DNAs were monitored by sequential elution of radioactively labelled DNA from HAP columns. Recoveries of input DNAs ranged from 87 to $100 \%$. When calf DNA was used as driver in control experiments to test for tracer self-association, corrected percent reassociated ranged from 0.34 to 3.9 with a mean of 1.4. Percent reassociation was corrected by setting homologous reassociation equal to $100 \%$. C, C. cinereus; $\mathrm{S}, C$. stercorarius. $\Delta \mathrm{T}_{\mathrm{m}}$ is defined as the difference between homologous and heterologous $\mathrm{T}_{\mathrm{m}}$

$\begin{array}{lll}\text { Driver/ } & \text { Reassociated (\%) } & \mathrm{T}_{\mathrm{m}},{ }^{\circ} \mathrm{C} \quad \Delta \mathrm{T}_{\mathrm{m}},{ }^{\circ} \mathrm{C} \\ \text { tracer } & \text { Actual Corrected } & \end{array}$

\begin{tabular}{lrrrl}
\hline Mitochondrial & & & & \\
C/C & 89.0 & 100.0 & 78.0 & - \\
S/S & 90.8 & 100.0 & 76.5 & - \\
S/C & 35.6 & 40.0 & 62.5 & 15.5 \\
C/S & 19.5 & 21.5 & 62.0 & 14.5 \\
Nuclear & & & & \\
C/C & 87.9 & 100.0 & 86.5 & - \\
S/S & 87.5 & 100.0 & 85.5 & - \\
S/C & 21.7 & 24.7 & 79.5 & 7.0 \\
C/S & 21.7 & 24.8 & 76.5 & 9.0 \\
\hline
\end{tabular}

was reassociated when $C$. stercorarius mtDNA was used as tracer. Furthermore, the heterologous duplexes that did form showed broad melting profiles (Fig. 4), with $\mathrm{T}_{\mathrm{m}}$ values approximately $15^{\circ} \mathrm{C}$ below those of the homologous duplexes. Both the low extent of cross hybridization and the reduced thermal stability of the duplexes that formed indicate that these two mtDNAs are not closely related in sequence.

\section{Nuclear DNA thermal melting studies}

The $\mathrm{G}+\mathrm{C}$ contents of the two nuclear DNAs were also calculated from native $T_{m}$ values and were found to be $55.0 \%$ (C. cinereus) and $58.4 \%$ (C. stercorarius). Both the nuclear and mitochondrial genomes of $C$. stercorarius are thus more $\mathrm{G}+\mathrm{C}$-rich than those of $C$. cinereus.

To assess the relatedness of the two nuclear genomes, DNAs were reassociated, bound to HAP, and thermally eluted. Highly repetitive sequences were first removed by HAP chromatography after reassociation of about $10 \%$ of the DNA. The value was based on the observation in the basidiomycete genomes studied to date $(C$. cinereus and Schizophyllum commune) that less than $10 \%$ of the nuclear DNA is repetitive (Dutta et al. 1972; Dons et al. 1979; Dons and Wessels 1980). The thermal elution profiles of the duplexes that formed are shown in Fig. 4 and summarized in Table 3. The homologous elution profiles were sharp, although the $C$. cinereus profile contained a small inflection in the lower temperature region, a feature absent from the denaturation profile of the native DNA. The $C$. cinereus inflection persisted when the elution profile was repeated with temperature increments of $1-1.5^{\circ} \mathrm{C}$ (data not shown). The reassociations were $87-88 \%$ complete, with $\mathrm{T}_{\mathrm{m}}$ values of $85.5^{\circ} \mathrm{C}$ (C. stercorarius) and $86.5^{\circ} \mathrm{C}$ (C. cinereus). As was the case for the mtDNAs, most of the nuclear DNA in the heterologous reactions did not reassociate. The duplexes formed had broad thermal elution profiles whose $T_{m}$ values were $7^{\circ}$ and $9^{\circ} \mathrm{C}$ below those of the homologous duplexes (Table 3 ).

In addition to the reassociations performed at $74{ }^{\circ} \mathrm{C}$, hybridizations were conducted at the reduced stringency of $65^{\circ} \mathrm{C}$ (data not shown). At this temperature, the $C$. stercorarius homologous elution profile was identical to that at $74^{\circ} \mathrm{C}$, but that of $C$. cinereus was somewhat broader, with a $2{ }^{\circ} \mathrm{C}$ reduction in the $\mathrm{T}_{\mathrm{m}}$. The extent of the heterologous reassociations only increased marginally (to $31 \%$ ), however, although the $\mathrm{T}_{\mathrm{m}}$ values were now approximately $15^{\circ} \mathrm{C}$ lower than for the homologous reassociations.

\section{Discussion}

We have constructed maps of restriction enzyme cleavage sites and the positions of structural genes for mtDNA from two basidiomycetes. The genomes are seen to vary substantially both in size and in gene order. In addition, the mtDNAs do not share restriction sites and nuclear DNA homology is low. Taken together, these data indicate that $C$. cinereus and $C$. stercorarius are not closely related species, consistent with their assignment on morphological grounds to different sections of the genus (Singer 1975).

Localization of genes was carried out by cross hybridization at reduced stringency with probes from coding regions of $S$. cerevisiae mtDNA. This strategy has proven successful based on DNA sequencing in a number of other organisms (Lang et al. 1983; Dujon 1983; Scazzochio et al. 1983), although exceptions have been reported (Johnson et al. 1982; Benne et al. 1983; Wright et al. 1982; Jamet-Vierny et al. 1984). In the present case, the approach is rationalized by the finding of a single hybridizing region on each mtDNA with eight of the nine probes employed.

\section{Subcellular location of var1 and ATPase 9 genes}

Results with varl are perhaps the most interesting of the data obtained with any of the nine probes. Only the $C$. stercorarius mitochondrial genome showed homology to 
varl and only the $C$. cinereus nuclear genome did so (Fig. 3). The simplest interpretation of these reciprocal results is that a copy of varl moved from one genomic compartment to the other in one of these organisms at some time after their divergence from a common ancestor. A precedent for the suggestion of different subcellular locations for varl is the presence of the major functional ATPase 9 gene on mtDNA in yeast (Macino and Tzagoloff 1979; Hensgens et al. 1979) and maize (Dewey et al. 1985) but on nuclear DNA in Neurospora, Aspergillus (Sebald et al. 1979; Turner et al. 1979), and, presumably, all metazoan animals. Since, as noted above, the two species examined in this study are placed taxonomically in different sections of the genus Coprinus, it will be interesting to examine more closely-related members of this genus with respect to subcellular localization of varl homology. It may then be possible to use the subcellular location of the varl gene as an aid in taxonomic placements.

Our blot transfer hybridization results show that the yeast ATPase 9 probe hybridizes with sequences present on mtDNA of both Coprinus species (Fig. 2) and on neither nuclear DNA (data not shown). These results must be interpreted in light of the finding of an intact copy of the ATPase 9 gene on Neurospora and Aspergillus mtDNAs (Agsteribbe et al. 1980; van den Boogaart et al. 1982; Brown et al. 1984). These mitochondrial copies may be non-functional, may function at a low level, or may function in non-exponentially growing cells. The predicted product more closely resembles the subunit 9 proteins in yeast and cow than the expressed Neurospo$r a$ or Aspergillus proteins (van den Boogaart et al. 1982; reviewed in Grossman and Hudspeth, 1985). By analogy, the possibility exists that our hybridization technique is detecting non-functioning (or secondarily functioning) mitochondrial copies, but is failing to detect more divergent (but primarily functioning) nuclear copies. It is important to stress that, in general, sequence homology detected with a DNA probe does not unambiguously establish parallel function.

\section{Size variation of mitochondrial genomes}

The great variation in size and organization found in the mitochondrial genomes of these Coprinus species is not surprising in light of previous findings among fungi, although the basis for such variation remains interesting and puzzling. In contrast to the extreme conservation of these features in vertebrate mitochondrial genomes (Wallace 1982; Gray 1982), fungal sizes range from $18.9 \mathrm{~kb}$ in Torulopsis glabrata (Clark-Walker et al. 1981) to $176.3 \mathrm{~kb}$ in Agaricus bitorquis (Hintz et al. 1985). MtDNA size estimates for the four basidiomycete species previously examined are 49.9 to $52.2 \mathrm{~kb}$ in Schizophyl- lum commune (Specht et al. 1983), $76 \mathrm{~kb}$ in Ustilago cynodontis (Mery-Drugeon et al. 1981), $98.3 \mathrm{~kb}$ in Agaricus brunnescens (Hintz et al. 1985), and 148.5 to $176.3 \mathrm{~kb}$ in $A$. bitorquis (Hintz et al. 1985), the ranges reflecting differences among strains or isolates.

Although sequence data are not yet available for Basidiomycete mtDNAs, DNA sequencing and RNA transcript analysis of some Ascomycete genomes reveal that much of the size variation can be accounted for by variation in the amount of non-coding sequences (Lang et al. 1983; Scazzocchio et al. 1983; Dujon 1983; Wright et al. 1982). We may consider the evolutionary source for this variation by visualizing three hypothetical scenarios: (1) a progenitor mitochondrial genome was very large and is becoming smaller; (2) a progenitor genome was small and is becoming larger; or (3) mitochondrial genomes are stochastically changing in size. If we assume that substantial size changes take place in an infrequent, punctuated manner (Butow et al. 1985), then the wide variation in size even between closely related species is consistent with any of the scenarios. We consider it unlikely, however, that the underlying mechanisms would be unidirectional, since mechanisms exist which promote both insertions and deletions, and both are known to occur. Thus, we favor the stochastic model. If changes can take place in both directions with rates that are not too different, then two limiting cases can be considered. Shrinkage of genomes to a minimal size might be nearly irreversible because the fraction of total nucleotides that could receive an insertion without inactivating a gene function would decrease hyperbolically. In addition, specific sites that might participate in genomic rearrangement, such as the GC-clusters on yeast mtDNA (Butow et al. 1985), would become progressively limited. Growth of genomes to a very large size, on the other hand, might cause them to become resistant to the stochastic processes of primarily non-selective deletions and insertions that would reduce genomes to minimal size. In other words, deletions in large genomes may not cause them to spiral into progressive shrinkage, since targets for insertion would still be plentiful. Interestingly, the mitochondrial genomes of higher animals and plants appear to resemble these limiting cases.

\section{Relatedness of mitochondrial and of nuclear genomes}

The lack of any clear correspondence between the patterns of restriction enzyme cleavage sites of the two Coprinus mtDNAs caused us to examine these DNAs by interspecies solution hybridization. The results were that (1) only a minority of each genome showed detectable homology to the other, and (2) the level of sequence divergence of the duplexes that did form was about $15 \%$, which is near the detection limit of the technique and 
must be regarded as a minimum value, whereas the amount of cross-reacting material must be regarded as a maximum value. The portion of each mitochondrial genome capable of forming an interspecies hybrid is numerically about equal to the total coding sequences expected, based on the $19 \mathrm{~kb}$ size (Clark-Walker et al. 1981; Del Giudice et al. 1981) and sequence (Lang et al. 1983) of the smallest known fungal mtDNAs and on the minimum size for encoding the known genes. It is reasonable that the coding regions would be the most conserved, although their identity to the renaturing fraction was not directly shown. Thus, the simplest interpretation of the data is that coding sequences form the bulk of the crosshybridizing mtDNA while non-coding sequences are too divergent to form interspecies duplexes.

We also examined the nuclear DNAs of these species by interspecific hybridization. As was the case for the mtDNAs, the majority of each genome (70-75\%) did not cross-hybridize; the duplexes that did form were about $8 \%$ divergent when reassociated at $25^{\circ} \mathrm{C}$ below the $\mathrm{T}_{\mathrm{m}}$ calculated for the homologous reaction, and $15 \%$ divergent when the stringency was reduced to $34^{\circ} \mathrm{C}$ below the $T_{m}$. These results indicate a surprising level of sequence divergence between members of the same genus. By contrast, DNA reassociations within the Ascomycete genus Neurospora showed greater than $80 \%$ crosshybridization and interspecies homologies only slightly $\left(4{ }^{\circ} \mathrm{C}\right)$ reduced from perfect duplexes (Dutta and Ojha 1972). In that same study, labelled $N$. crassa DNA was also reassociated with unlabelled C. cinereus or Mucor azygospora DNA with the findings of $10-15 \%$ reassociation and reduction in thermal stability of 7 or $8{ }^{\circ} \mathrm{C}$. However, within some yeast genera, species with less than $20 \%$ cross hybridization have been found (Price et al. 1978). It may be that the sequences capable of reassociating in distantly related species correspond to the coding fraction of these genomes, which have been conserved during evolution. By analogy to the Achlya genome, and taking into account the rDNA repeat and assuming there are no other repetitive sequences, approximately $10 \%$ of the $C$. cinereus genome may correspond to coding sequences (Timberlake et al. 1977). Thus, it seems likely that, in these morphologically similar but evolutionarily distant basidiomycetes, primarily coding sequences have remained similar enough to cross-hybridize in both the nuclear and mitochondrial genomes; however, our experiments do not eliminate the possibility that some coding sequences do not cross-hybridize and/or that some of the cross-hybridizing material does not code.

Acknowledgements. We wish to thank Deborah S. Shumard for her assistance with many technical aspects and for the preparation of some figures and Henry Burr (Wayne State University) for the use of his facilities and for his helpful discussions of the DNA reassociation and thermal elution work. Our colleagues Ro- bert B. Helling, Jeffrey D. Palmer and Robert L. Shaffer kindly provided critical comments on the manuscript. We thank Jennifer Comell for typing the manuscript and David Bay for help with the figures. C. A. W. gratefully acknowledges support from The University of Michigan Predoctoral Genetics Training Program (N.I.H. National Research Service Award no. 1-T32-GM$07544-07)$. This work was supported by N.I.H. grants GM-28851 (G.P.M.) and GM-26546 (L.I.G.).

\section{References}

Agsteribbe E, Samallo J, DeVries H, Hensgens LAM, Grivell LA (1980) Sequence homologies between the mitochondrial DNAs of yeast and Neurospora crassa. In; Kroon AM, Saccone $C$ (eds) The organization and expression of the mitochondrial genome. Elsevier/North-Holland Biomedical Press, Amsterdam, pp 51-60 (Developments in genetics, vol 2)

Benne R, DeVries BF, Van den Burg J, Klaver B (1983) Nucleic Acids Res 11:6925-6941

Bonitz SG, Coruzzi G, Thalenfeld BE, Tzagoloff A, Macino G (1980) J Biol Chem 255: 11927-11941

Bonner TI, Brenner DJ, Neufeld BR, Britten RJ (1973) J Mol Biol $81: 123-135$

Britten RJ, Graham DE, Neufeld BR (1974) Methods Enzymol $29: 363-418$

Brown WM (1980) Proc Natl Acad Sci USA 77:3605-3609

Brown WM, George M Jr, Wilson AC (1979) Proc Natl Acad Sci USA 76:1967-1971

Brown WM, Prager EM, Wang A, Wilson AC (1982) J Mol Evol $18: 225-239$

Brown TA, Ray JA, Waring RB, Scazzochio C, Davies RW (1984) Curr Genet $8: 489-492$

Butow RA, Perlman PS, Grossman LI (1985) Science 228:1496 to 1501

Clark-Walker GD, McArthur CR, Daley DJ (1981) Curr Genet $4: 7-12$

Cohn VH, Thompson MA, Moore GP (1984) J Mol Evol 20:3137

Coruzzi G, Tzagoloff A (1979) J Biol Chem 254:9324-9330

Del Giudice L, Wolf K, Bueno C, Manna F (1981) Mol Gen Genet $181: 306-308$

Dewey RE, Schuster AM, Levings CS III, Timothy DH (1985) Proc Natl Acad Sci USA 82:1015-1019

Dons JJM, Wessels JGH (1980) Biochim Biophys Acta 607 : 385396

Dons JJM, DeVries OMH, Wessels JGH (1979) Biochim Biophys Acta $563: 100-112$

Dujon B (1983) Mitochondrial genes, mutants and maps: a review. In: Schweyen RJ, Wolf K, Kaudewitz F (eds) Mitochondria 1983: nucleo-mitochondrial interactions. de Gruyter, Berlin New York, pp 313-329

Dutta SK, Ojha M (1972) Mol Gen Genet $114: 232-240$

Dutta SK, Penn SR, Knight AR, Ojha M (1972) Experientia 28 : $582-584$

Efstratiadis A, Posakony JW, Maniatis T, Lawn RM, O'Connell C, Spritz RA, DeRiel JK, Forget BG, Weissman SM, Slightom JL, Blechl AE, Smithies O, Baralle FE, Shoulders CC, Proudfoot NJ (1980) Cell 21:653-668

Ferris SD, Wilson AC, Brown WM (1981) Proc Natl Acad Sci USA $78: 2432-2436$

Fox TD (1979) J Mol Biol 130:63-82

Geiduschek EP (1962) J Mol Biol 4:476-487

Gray MW (1982) Can J Biochem 60:157-171

Gray MW, Doolittle WF (1982) Microbiol Rev 46:1-42 
Grossman LI, Hudspeth MES (1985) Fungal mitochondrial genomes. In: Bennett JW, Lasure LL (eds) Gene manipulations in fungi. Academic Press, New York London, pp 65-103

Hensgens LAM, Grivell LA, Borst P, Bos JL (1979) Proc Natl Acad Sci USA 76:1663-1667

Hintz WE, Mohan M, Anderson JB, Horgen PA (1985) Curr Genet $9: 127-132$

Hudspeth MES, Shumard DS, Tatti KM, Grossman LI (1980) Biochim Biophys Acta 610:221-228

Hudspeth MES, Ainley WM, Shumard DS, Butow RA, Grossman LI (1982) Cell 30:617-626

Hudspeth MES, Shumard DS, Bradford CJR, Grossman LI (1983) Proc Natl Acad Sci USA 80:142-146

Jamet-Vierny C, Begel O, Belcour L (1984) Eur J Biochem 143 : 389-394

Johnson BJB, Hill GC, Fox TD, Stuart K (1982) Mol Biochem Parasitol $5: 381-390$

Lang BF, Ahne F, Distler S, Timkl H, Kaudewitz F, Wolf $\mathrm{K}$ (1983) Sequence of the mitochondrial DNA, arrangement of genes and processing of their transcripts in Schizosaccharomyces pombe. In: Schweyen RJ, Wolf K, Kaudewitz F (eds) Mitochondria 1983: nucleo-mitochondrial interactions. de Gruyter, Berlin New York, pp 313-329

Li M, Tzagoloff A (1982) J Biol Chem $254: 4617-4623$

Macino G, Tzagoloff A (1979) J Biol Chem $254: 4617-4623$

Macino G, Tzagoloff A (1980) Cell 20:507-517

Maniatis T, Fritsch EF, Sambrook J (1982) Molecular cloning: a laboratory manual. Cold Spring Harbor Laboratory, Cold Spring Harbor, NY

Marmur J, Doty P (1962) J Mol Biol 5:109-118

McDonell MW, Simon MN, Studier FW (1977) J Mol Biol 110 : 119-146

Mery-Druge on E, Crouse EJ, Schnitt JM, Bohnert HJ, Bernardi G (1981) Eur J Biochem 114:577-583

Nobrega FG, Tzagoloff A (1980) J Biol Chem 255:9828-9837

Perler F, Efstratiadis A, Lomedico P, Gilbert W, Kollander R, Dodgson J (1980) Cell 20:555-566

Price CW, Fuson GB, Phaff HJ (1978) Microbiol Rev 42:161193

Scazzochio C, Brown T, Waring RB, Ray JA, Davies RW (1983) Organization of the Aspergillus nidulans mitochondrial genome. In: Schweyen RJ, Wolf K, Kaudewitz F (eds) Mito- chondria 1983: nucleo-mitochondrial interactions. de Gruyter, Berlin New York, pp 303-312

Schildkraut C, Lifson S (1965) Biopolymers 3:195-208

Sebald W, Hoppe J, Wachter E (1979) Amino acid sequence of the ATPase proteolipid from mitochondria, chloroplasts and bacteria (wild type and mutants). In: Quagllariello E, Palmieri F, Papa S, Klinkenberg M (eds) Functions and molecular aspects of biomembrane transport. Elsevier/North-Holland Biomedical Press, Amsterdam, pp 63-74 (Developments in bioenergetics and biomembranes, vol 3)

Shaffer RL (1975) Mycologia $67: 1-18$

Sibley CG, Ahlquist JE (1983) Curr Ornithol 1:245-293

Sibley CG, Ahlquist JE (1984) J Mol Evol 20:2-15

Singer R (1975) The agaricales in modern taxonomy, 3rd edn. Cramer, Lehre

Sor F, Fukuhara H (1980) CR Acad Sci Ser D 291:933-936

Sor F, Fukuhara H (1983) Nucleic Acids Res 11:339-348

Southern EM (1975) J Mol Biol 98:503-517

Specht CA, Novotny CP, Ullrich RC (1983) Exp Mycol $7: 336-$ 343

Thalenfeld BE, Tzagoloff A (1980) J Biol Chem 255:6173-6180

Timberlake WE, Shumard DS, Goldberg RB (1977) Cell 10:623 to 632

Turner G, Imam G, Küntzel H (1979) Eur J Biochem $97: 565-$ 571

van den Boogaart P, Samallo J, Agsteribbe E (1982) Nature (London) 298:187-189

Walker WF, Doolittle WF (1982) Nature (London) 299:723724

Wallace DC (1982) Microbiol Rev $46: 208-240$

Whittaker RH (1969) Science 163:150-160

Wilson AC, Carlson SS, White TJ (1977) Annu Rev Biochem 46: $573-639$

Wright RM, Horrum MA, Cummings DJ (1982) Cell 29:505-515

Zassenhaus HP, Farrelly F, Hudspeth MES, Grossman LI, Butow R (1983) Mol Cell Biol 3:1615-1624

Communicated by C. W. Birky, Jr.

Received September 12 / October 18, 1985 